\title{
The Role of Organizational Development to Improve the Jordanian Universities Effectiveness
}

\author{
Husam Mahmmud Jamil Abu-Hamour ${ }^{1}$ \\ ${ }^{1}$ Faculty of Planning and Management, Balqa Applied University, Jordan \\ Correspondence: Husam Mahmmud Jamil Abu-Hamour, Faculty of Planning and Management, Balqa Applied \\ University, Jordan. Tel: 962-797-329-000; 962-777-329-000. E-mail: abohamor_hosam@yahoo.com
}

Received: May 17, 2012 Accepted: August 2, 2012 Online Published: October 1, 2012

doi:10.5539/ijbm.v7n19p76 URL: http://dx.doi.org/10.5539/ijbm.v7n19p76

\begin{abstract}
This study aimed to clarify the role of organizational development to improve the effectiveness of the Jordanian universities. The study was applied on (80) employers in the units of planning, development and quality assurance within six Jordanian universities, including three public and three private universities. A questionnaire was developed in order to measure the study variables. It consisted of (40) items, of which (30) items for measuring organizational development and (10) for measuring the effectiveness of the university. The study instrument had acceptable indications of validity and reliability. The study results showed that the reality of organizational development in the Jordanian universities is high, the level of effectiveness of the Jordanian universities is high, and the presence of a statistically significant impact regarding development of the organizational dimensions (organizational factors, material potentials, technological means) in improving the effectiveness of the Jordanian universities. The study recommended for the necessity to work on enabling the appropriate delegation of authority for employees in the units of organizational development at Jordanian universities and focusing on the feedback from the implementation of organizational development processes.
\end{abstract}

Keywords: organizational development, change, effectiveness, universities, higher education

\section{Introduction}

Various organizations encounter at present to many challenges where the most important represented in the instability surrounding environment, increasing in competition, changing of customers' demands and expectations, maintaining the consistency organization's pillars, actualizing efficiency, effectiveness and profitability. In addition to what individuals encounter within the organizations of challenges related to achieving an acceptable degree of satisfaction, the treatment of prescription in skills and experiences, and achieving their goals through the achievement of organizational goals. Furthermore, the problem of strategic partner entry in organizations and the disposal of large numbers of workers in these organizations. (French; Bell \& Zawacki, 2004).

Consequently, the need appeared for organizational development among organizations and individuals alike to help in overcoming these challenges and problems, give organizations the ability to survive and achieve its objectives efficiently and effectively. From the above we note that the process of development is renewed, continuous, developed, purposeful and well planned work. It can be partially or radically change includes the employees and the organizing in its various dimensions in order to achieve the required efficiency and effectiveness (Brown, 2011).

The perception of organizational development in most developing countries relies on the administrative governmental system and on the different approaches of traditional and modern organizational development that led to a state of uncertainty in understanding the objectives of organizational development which seeks to achieve. The traditional approaches influenced by bureaucratic and classic theory It involves structural, legal and official aspects of the administrative system of government. However, recent approaches highlights the behavioral and humanistic aspects since they concerned with man, his motives and needs and give the importance for the external environment, working conditions and work flexibility as it addresses the group working methods (Forbes, 1998).

In the field regarding the use of management change strategies and their relationship to the organization's effectiveness, Cameron \& Whetten (1983) explained how the organization responses and adapts to surrounding 
environmental change. Herman and Renz (1998) proved that change strategies impact the effectiveness of the organization where the organization utilizes strategies that enable them to adapt to the change in the laws and customs in the surrounding environment. Therefore, this study seeks to assess the organizational development efforts in the Jordanian universities and clarifies the role of these efforts in improving the effectiveness of the Jordanian universities.

\section{The Study Problem}

The organizational development is considered one of the most important factors that help organizations to survive in the face of changes (political, economic, social) and accelerative technological progress. Jordanian universities sought to achieve progress in the field of organizational development. However, the efforts of organizational development are not sufficient or encounter obstacles and problems within universities. Perhaps this is due to the resistance for development programs in universities in particular the fear of change where the processes of organizational development carries with it the seeds of change whether it was a radical or partial change. Therefore, this study emerged to explore the role of organizational development to improve the effectiveness of the Jordanian universities. The problem of the study lies in answering the following questions:

1) What is the reality of organizational development in the Jordanian universities?

2) What is the level of effectiveness of the Jordanian universities?

3) What is the role of organizational development to improve effectiveness of the Jordanian universities?

\section{Importance of the Study}

The importance of this study stems from its consideration for the most important administrative issues in the management of administrative Sciences that is the organizational development. It is considered the main concern among the leaders of various organizations in order to give their organizations the ability to progress, prosperity and meet the needs of the public. It also provides a realistic assessment of the process of organizational development in the Jordanian universities. The importance of the study is represented in attempting to predict the effectiveness of the Jordanian universities through the application of organizational development programs in those universities. This study aims to support efforts in making the desired change in Jordanian universities, as well as trying to raise the level and efficiency of performance of organizational development units in the Jordanian universities. On the other hand, this study enriches the academic field and management literature in the Arab environment in general and Jordan in particular by its findings and recommendations.

\section{Organizational Development}

\subsection{The Concept of Organizational Development}

Contemporary administrative trends in the field of developing organizations outlined to utilize the term Organizational Development (OD) as a range of intervention means that aim to cause change in skills, activities, tools and methods implemented to help the organization to be more efficient. The organizational development began as one of the applications of behavioral science to solve the problems faced by the organization in the late forties specifically, as a result of sociology pioneers research such as Kurt Lewin. He was greatly influenced by the work of psychologists like Carl Rogers and Abraham Maslow. The Organizational Development term refers in its origin to Robert Blake and Jane Mouton who invented the method of network management. Herbert Shepard is considered as one of the pioneers in the field of organizational development as well as Ritchard Beckhard who imputed this right for himself. Regardless of who is credited with the term, it was shown specifically in 1957 as a result of the approaches, the efforts, the research of National Training Laboratories and Reconnaissance Research Center in the United States that was supervised by Kurt Lewin in 1945 (Brown, 2011)

One of the definitions which dealt with the concept of organizational development, is the definition of Beckhard (1969): Organizational development is an " planned effort at the level of the organization as a whole, supported by the high management in order to increase the effectiveness and well-being of the organization through planned interventions in the processes taking place in organizing, utilizing in that the knowledge provided by behavioral sciences. Beckhard focused on the term "Effort" synonymously with "development" that is administrated through behavioral meddling in all operations and activities of the organization by the high management which ultimately leads to increase the productivity effectiveness of the organization. The following figure that is provided by the researcher shows the pillars of Beckhard's definition for the organizational development. 
The definition of French, Bell and Zawacki (2004) is one of the comprehensive definitions that explained the concept of organizational development that pointed at "the development of organizations is long-term effort managed and supported by the high management in order to develop the future vision among the organization, empowerment, learning, and problem-solving processes through the group ongoing operations for the management of organization's culture with emphasizing particularly on the culture of work teams and teams formations using facilitative role of the advisor, the theories and techniques of behavioral science including scientific research ".

French, Bell \& Zawacki (2004) focused on the concept of organizational development through a long-term effort which may require time in order to bring about organizational change. In order for success and productivity of this effort, it should be adopted by an integrated management with encouraging its practice. The definition emphasized that the high management in the organization is responsible for the management and encouraging the efforts of change. As a matter of course, the high management aimed here to develop the future vision of the organization, enabling it to solve problems and management the culture of the organization and the culture of individuals interactively so by relying on theories and techniques of behavioral science including scientific research which reflects the model of participation between leaders and members of the organization to diagnose problems and find solutions to them collectively.

Donald Brown (2011) hold the view that organizational development includes "long-term efforts, and the programs that aim at improving the organization's ability to survive by changing its operations in the decision-making or renewal. Organizational development also includes moving towards organizational adaptation and actualizing excellence through meeting the desire of individuals to growth and development consistently with the organization's objectives".

\subsection{Impediments of Organizational Development in Jordan}

The organizational development efforts may encounter resistance through resisting methods used by managers in order to bring about change. Al Maslamani (1999) summarizes these impediments in five types:

- Administrative impediments: The most important of these obstacles represented in increasing the number of employees on the actual need for the administrative systems and the dominant of some bad habits among them, including resistance to change, and the absence of human relations between high management and management levels.

- Physical impediments: These obstacles are represented in financial resources and technical and technological capabilities.

- Legal impediments: some of these constraints are prescription of legislation and laws related to the work, the low level of control and follow-up system, and the low level of commitment to principles and rules of selection and recruitment of staff and therefore the arrival of people who are not qualified to some of the important administrative positions.

- Social impediments: the dominancy of some bad social habits which have a negative impact on the administrative system. Some of these habits are the prevalence of private loyalties such as tribal and regional, and the spread of nepotism and favoritism.

- Political impediments: the appropriate political climate plays surrounding organization plays an important role in the organizational development. Consequently, the political climate prevailed with commotion, instability and conflict between the various political forces in the society impacts negatively on the management development programs.

\section{Effectiveness}

Forbes (1998) identified four stages for the development of organizational effectiveness frameworks assessing which are as follows:

- goal attaining: the effectiveness of the organization is measured through the degree of achieving its objectives.

- System resources: in which the viability of the organization is equivalent to its organizational effectiveness. This effectiveness is measured through the extent of success among the organization in utilizing the institutional, political and economical resources to maintain its viability continuity.

- Reputation: effectiveness is measured through self-reports of individuals in the organization such as staff and customers. 
- Competitive Values: it includes three dimensions: the organizational vision, organizational structure and the organizational results and methods. The effectiveness can be measured in accordance with them in several ways simultaneously.

Some researchers restricted the effectiveness in the first frame that is goal attaining, including Connolly et al (1980) who considered that the effectiveness is the degree to reach the target by mutual affected parties within the organization. Moreover, they confirmed that the broad view of effectiveness includes hold accountability for decision makers in the organization regarding the validity of these decisions and the extent of its correctness to meet the economic and non-economic goals and values of the organization. Seashore (1983) hold the view that the framework for goal attaining does not mean just put a definition for organizational effectiveness rather than creating new conceptual framework that assist in thinking coherently and acting wisely by those who their leadership roles are imposed on them within the organization. Also those who imposed by research duties as researchers should choose appropriate definition for effectiveness that matches the goals they seek to achieve them.

In contrast, another model known as the model of system resources appeared. It was outlined by Katz \& Kahn (1978) and Yuchtman \& Seashore (1967). It is a model that equalizes the effectiveness of the organization with the ability to maintain continuity. Effectiveness can be measured here by measuring the extent of organization's success in utilizing institutional, economic and political resources in order to maintain its viability. This model is considered to be the main alternative to the goal model. Cameron (1982) and Cameron \& Whetten (1983) pointed to that there is no universal model of the organization effectiveness and therefore it is necessary and important to develop new models to determine the effectiveness and trying to develop theories of their own.

Other researchers such as Kushner \& Poole (1996) outlined that the organization's ability to obtain resources is an important dimension in the effectiveness of organizations. Others such as Murray \& Tassie (1994) focused on the effectiveness of internal processes in the organization that related to topics such as cost per unit of product or service provided by the organization. This means that the maintenance of costs down is a fundamental pillar to reach the financial results desired as well as achieving the productivity, quality and speed required for the programs changes that reflect to the extent of rapid responses by programs to the changes in user's requests. On the other hand, others such as Murray \& Tassie (1994) focused on the effectiveness of internal processes within organization. In contrast, the organizational effectiveness linked with using the correct administrative procedures in the organization.

\section{Methodology}

This study relied on the descriptive approach through reviewing the management literature related to organizational development and effectiveness and by reference to previous studies related to the subject of study. In addition, it relied on the implementation of field methodology to test the study's hypotheses and access to their results by relying on a questionnaire developed for achieving the purposes of this study.

\subsection{Members of the Study}

The study was applied on in the units of planning, development and quality assurance in six Jordanian universities including three public and three private universities. 111 questionnaires were distributed where 95 of them were retrieved that forms $86 \%$ while 15 were excluded because of lacking suitability for analysis. Thus, the study was applied on 80 employees in the units of planning, development and quality assurance in those universities. Table 1 shows the characteristics of the study sample.

Table 1. Distribution of study sample based on personal and vocational variables

\begin{tabular}{cccc}
\hline Variable & Variable categories & Number & Percentage \\
\hline \multirow{2}{*}{ Social status } & male & 43 & 53.8 \\
& female & 37 & 46.3 \\
Qualification & Bachelor & 74 & 92.5 \\
& High studies & 6 & 7.5 \\
& Less than 5 years & 12 & 15 \\
Years of Experience & From 6-10 years & 22 & 27.5 \\
& From 11-15 years & 36 & 45 \\
& More than 15 years & 10 & 12.5 \\
\hline
\end{tabular}




\subsection{Study Instrument}

An instrument was developed for achieving the purposes of the study by referring to theoretical literature related to organizational development and effectiveness. The study instrument included (40) items that measure the reality of organizational development and effectiveness of universities relying on five points Likert Scale. Items weights were calculated as follows: strongly agree represents (5 degrees), I agree represents (4 degrees), neutral represents (3 degrees), I do not agree represents (2 degrees) and strongly disagree represents (1 degree). The items (1-30) measured the independent variable (the reality of organizational development). These items were categorized into three dimensions: the first, organizational factors and measured by items (1-13), the second, of technological means and measured by items (14-22), and the third, material potentials and measured by items (23-30). As items (31-40) measured the dependent variable (effectiveness of the university).

The instrument relied on the standard related to the value of arithmetic mean for the items. The value of arithmetic mean greater than (3.5) indicates high level of estimation for the study sample. The value of the arithmetic mean equals (2.5 -3.49) indicates a moderate level while the arithmetic mean of (2.49) and below indicates low level in comparison with the arithmetic mean.

\subsection{Instrument's Validity}

The study instrument was offered on a number of specialists in the field of business management in order to recognize the extent of adequacy and conformity of language wording for the questionnaire's items in addition to what extent the instrument items are adequate for its dimension. The arbitrators' comments and suggestions were taken considerably. Some items were reformulated in the light of these observations.

\subsection{Instrument's Reliability}

The coefficient of internal consistency for the study instrument was obtained that indicates the degree of consensus among responders to the study instrument's items based on Cronbachs' Alpha equation for the variables of the study. the values of reliability were high. These are good and acceptable in research and human studies. Table 2 indicates the consistency coefficients.

Table 2. Coefficient internal consistency coefficient for the study variables

\begin{tabular}{cccc}
\hline Items & variables & factors & $\begin{array}{c}\text { Cronbach } \\
\text { alpha }\end{array}$ \\
\hline $1-13$ & reality of & organizational factors & 0.94 \\
$14-22$ & OD & technological means & 0.88 \\
$23-30$ & & Material potentials & 0.89 \\
$31-40$ & & University effectiveness & 0.91 \\
\hline
\end{tabular}

\subsection{Statistical Treatment}

Statistical packages for the Social Sciences (SPSS) were implemented to test the hypotheses of the study. frequencies, percentages, means, standard deviations, and multiple regression test were used.

\section{Results and Discussion}

\subsection{The Reality of Organizational Development in the Jordanian Universities}

It appears from table (3) that the reality of organizational development in the Jordanian universities is high where the general mean reached to (4.06). after analyzing the dimensions of organizational development, it is clear that organizational factors dimensions ranked firstly with an arithmetic mean value of (4.07), followed by the material potentials with an arithmetic mean reached to (4.06) and the technological means dimension came at the last rank with an arithmetic mean reached to (4.04). The level of these dimensions was high.

This result Explains that the levels of organizational development in the Jordanian universities was moderate among those responsible on development programs. As these efforts achieved remarkable successes at the university level, it did not reach the degree of integration and convenience between each of the university goals and the employees goals because of the degree development programs utilization supplied by high management without the involvement of employees in contributing to the setting of development programs. With regard to organizational factors, the stakeholders on the organizational development programs focused to develop 
organizational and structural aspects of the Jordanian universities, particularly with regard to simplification of work procedures. But these efforts did not achieve the desired change regarding undermine the authority as a private gain for workers in those universities. The efforts of development in Jordanian universities succeeded in the introduction of modern devices and tools into administrative work while creating data and information databases relating to the provision of the necessary information needed to rationalize the decision-making process in these universities did not achieve the desired level since this process requires intensive and great efforts from one hand, and a degree of disclosure of their information from the other hand. Also the development efforts succeeded in providing the needed financial support for the provision of modern devices and software which is one of the requirements of the desired change especially those of modern management strategies such as restoring structure and comprehensive quality management.

Table 3. Arithmetic means and standard deviations of the reality of organizational development in the jordanian universities in descending order

\begin{tabular}{cccccc}
\hline $\begin{array}{c}\text { Dimension } \\
\text { number }\end{array}$ & $\begin{array}{c}\text { Dimensions of } \\
\text { e-government }\end{array}$ & $\begin{array}{c}\text { Arithmetic } \\
\text { mean }\end{array}$ & $\begin{array}{c}\text { Standard } \\
\text { deviation }\end{array}$ & Rank & Level \\
\hline 1 & Organizational factors & 4.07 & 0.587 & 1 & high \\
2 & Material potentials & 4.06 & 0.639 & 2 & high \\
3 & Technological means & 4.04 & 0.745 & 3 & high \\
& Overall & 4.06 & 0.546 & - & high \\
\hline
\end{tabular}

\subsection{The Effectiveness of the Jordanian Universities}

The study results showed that the level of effectiveness among Jordanian universities was high with arithmetic mean value of (3.81). This result explains that public universities achieved high levels of efficiency as a result of the clarity of its goals and policies and as clarity of the University's vision among its employees regardless of their career position which contributed directly to achieving effectiveness. The main concern among universities was achieving the highest degrees of implementation of its available resources, especially they are passing along new stage characterized with evolution and rapid change. The universities kept to measure the degree of achieving the desired goals. Thus, it was necessary to develop learning objectives that are applicable, measurable and can be assessed since it is a main part of the educational process and as one of the most important indicators of the universities' success or failure to achieve its general mission. The goals of University are not accepted by all faculty members. The reason for this may be due to the difference among faculty members related to the various Arab cultures.

Universities realized definitively that ensuring their survival and viability lies in conformity with scientific and technological progress. The faculty members felt with high levels of satisfaction for their universities and this may be due to that they consider themselves an integral part of their universities as well as the university sought to meet the needs, desires and expectations of the faculty members in a high degree. Furthermore, the faculty members rely mainly on their university to achieve their needs and desires without focusing on themselves. Finally, universities set strategies considering implementing its available resources to achieve the highest return from these resources so as to keep pace with the development and continued progress within. But it still trying to interact with changes in the regional environment because this environment is characterized by instability and it rely heavily on regional Environment in the provision of faculty members.

\subsection{The Role of Organizational Development to Improve the Eeffectiveness of the Jordanian Universities}

It appears from table (4) the existence of a statistical significance impact of organizational development to improve the effectiveness of the Jordanian universities as the value of $(F)$ reached (52.029) at a level of significance $(0.000)$ that is the lowest level of significance $(\alpha=0.05)$. It appears also that the organizational development in this model explains the amount (67.3\%) of the variation in the effectiveness of the Jordanian universities that is a relatively high explanatory power. The table indicates also that the independent dimensions (organizational factors, material potentials, technological means) have an impact on improving the effectiveness of the Jordanian universities as the value of $(\mathrm{t})$ reached to $(2.374,2.983,5.069)$ respectively with a probability value reached $(0.019,0.003,0.000)$ respectively which is less than the level of significance $(\alpha=0.05)$. The 
comparison of beta coefficients for these dimensions shows that the technological means dimension is the strongest one that effect in improving the effectiveness of the Jordanian universities as the value of a beta reached (0.323). Based on these results, the alternative hypothesis is accepted, which states that there is a statistically significant impact of the organizational development with its dimensions (organizational factors, material potentials, technological means) to improve the effectiveness of the Jordanian universities.

Table 4. Results of multiple regression test to test the impact of organizational development to improve the effectiveness of the jordanian universities

\begin{tabular}{ccccccc}
\hline $\begin{array}{c}\text { independent } \\
\text { variables }\end{array}$ & Beta & $\begin{array}{c}\mathrm{t} \\
\text { Calculated } \\
\text { value }\end{array}$ & $\begin{array}{c}\mathrm{t} \\
\text { Significance } \\
\text { level }\end{array}$ & $\mathrm{R}^{2}$ & $\begin{array}{c}\mathrm{f} \\
\text { Calculated } \\
\text { value }\end{array}$ & $\begin{array}{c}\text { Significance } \\
\text { level }\end{array}$ \\
\hline $\begin{array}{c}\text { Organizational } \\
\text { factors }\end{array}$ & 0.177 & 2.374 & $0.019^{*}$ & & & \\
$\begin{array}{c}\text { Technological } \\
\text { means }\end{array}$ & 0.229 & 2.983 & $0.003^{*}$ & $0.673^{*}$ & 52,029 & $0.000 *$ \\
material potentials & 0.323 & 5.069 & $0.000^{*}$ & & & \\
\hline
\end{tabular}

* Statistically significant at the level $(\alpha=0.05)$

\section{Recommendations}

In light of the results of the study, a set of recommendations can be provided that aimed at activating the role of organizational development programs to improve the effectiveness of the Jordanian universities. These recommendations are:

- The Need to work on enabling the appropriate delegation of authority for employees in the units of OD at Jordanian universities. In addition to focus on the feedback from the implementation of organizational development.

- Work on the development of rules and regulations constantly to keep up with rapid changes in the work environment in Jordanian universities. Furthermore, the need to disseminate the philosophy of organizational development with its future dimensions and aspirations and create harmony and compatibility with the values and principles of staff so that there is a degree of integration and lack of conflict between them.

- Work on the creating data and information databases in Jordanian universities that are constantly updated since it is an important element in the rationalization of effective decision-making process to be available in a timely manner when needed during the organizational development.

- Work to support social relations among employees to take advantage of its positive effects in supporting the efforts of organizational development at the same time reducing resisting it.

- Universities should focus on the employment of their resources to achieve the university goals. By studying the economic feasibility of projects that will be carried out by using a cost analysis of return (CEA) and the participation of faculty members in decision-making's committees in projects that the university plans to carry out. Furthermore, setting long-term strategically plans to cope with rapid environmental changes.

\section{References}

Al. Maslamani, \& Hashim, Ali. Issa. (1999). The assessment of Effectiveness of Management Development and its Constraints in Jordan: the staff's point of view. Unpublished MA Thesis, University of Al al-Bayt.

Beckhard, R. (1969). Organization Development: Strategies and Models. Reading, MA: Addison-Wesley. ED: 037623.

Brown, Donald R. (2011). Experiential Approach to Organization Development (8th Ed.). New Jersey: Pearson 
Prentice Hall. ISBN-10: 0136106897.

Cameron, K., \& Whetten, D. (1983). Organizational Effectiveness: A Comparison of Multiple Models. New York: Academic Press. ISBN: 0121571807.

Cameron, \& Kim, S. (1982). An Empirical Investigation of The Multiple Constituencies Model of Organizational Effectiveness, Washington: National Center for Higher Education Management Systems. ED: 271069.

Connolly, Terry, Edward J. Conlon, \& Stuart Jay Deutsch. (1980). Organizational Effectiveness: A Multiple-Constituency Approach. Academy of Management Review, 5(2), 211-218. http://dx.doi.org/10.5465/AMR.1980.4288727

Forbes, D. P. (1998). Measuring the Unmeasurable: Empirical studies of Nonprofit Organization Effectiveness from 1977-1997. Nonprofit and Voluntary Sector Quarterly, 27(2), 183-202. http://dx.doi.org/10.1177/0899764098272005

French, L. Wendell; Bell, Cecil, H., Zawacki, \& Robert A. (2004). Organization Development and Transformation( 6th Ed.), McGraw-Hill Inc. ISBN-10: 0072481676.

Herman, R. D., \& Renz, D. O. (1998). Nonprofit Organizational Effectiveness: Contrasts Between Especially Effective and Less Effective Organizations. Nonprofit Management and Leadership, 9(1), 23-38. http://dx.doi.org/10.1002/nml.9102

Katz, D., \& Kahn, R. (1978). The Social Psychology of Organizations (2nd Ed). New York: John Wiley \& Sons. ISBN-10: 0471023558.

Kushner, R. J., \& Poole, P. P. (1996). Exploring Structure-Effectiveness Relationships in Nonprofit Arts Organizations. Nonprofit Management \& Leadership, 7(2), 119-136. ISSN: 10486682.

Murray, V., \& Tassie, B. (1994). Evaluating the Effectiveness of Nonprofit Organizations. In R. D. Herman (Ed.). The Jossey-Bass Handbook of Nonprofit Leadership and Management. San Francisco, CA: Jossey-Bass Publishers. ISBN-10: 1555426514.

Seashore, S. (1983). A Framework for an Integrated Model of Organizational Effectiveness. In K. Cameron, D. Whetten, (Eds.) Organizational Effectiveness: A Comparison of Multiple Models. New York: Academic Press, Inc. ISBN: 01215718079780121571801.

Yuchtman, E., \& Seashore, S. E. (1967). A System Resource Approach to Organizational Effectiveness. American Sociological Review, 32(6), 891- 903. ISSN: 00031224. 